\title{
ANALISIS PERMASALAHAN PENGEMBALIAN BANTUAN MODAL KERJA BERGULIR DENGAN METODE ZOPP: STUDI KASUS DI BKM BERKAH MULYO, YOGYAKARTA
}

\author{
Arief Fahmie \\ Universitas Islam Indonesia
}

INTISARI

Penelitian ini bertujuan untuk menganalisis permasalahan bantuan moda koja bergulir di BKM Berkah Mulyo Yogyakarta denganmenggunakan metode ZOPP (Ziel' Orientierte Project Planung = Perencanaan Proyek Beorientasi pada Tujuan) sehingga dapat diupayakan langkah-langkah penyelesaiannya.

Berdasarkan data penelitian maka dapat dijdentifikasikan bahwa permasalahn tersebut dipengaruhi oleh faktor situasional, institusional, dan individual. Analisis lebih lanjut menyimpulkan bahwa intervensi yang dapat dilakukan adalah survey o KSM yang mengajukan permohonan bantuan modal kerja, sosialisasi kepada masyarakat, melakukan Pelatihan motivasi dan ketrampilan wirausaha, kewajiban mengikuti pelatihan bagi KSM yang mengajukan permohonan bantuan modal kerja. dan perbaikan susunan pengurus.

Kata Kuncl: Bantuan modal kerja bergulir, peran, ZOPP

\section{PENDAHULUAN}

B erbagai program penanggulangan kemiskinan telah dimulai sejak Pelita I dan menjangkau seluruth pelosok tanah air. Upaya tersebut telah menghasilkan perkembangan yang positif tetapi krisis moneter dan ekonomi yang melanda Indonesia sejak tahun 1996 telah menghapus usaha-usaha pengentasan kemiskinan yang telah dilakukan. Krisis tersebut telah menimbulkan lonjakan pengangguran dan dengan cepat meningkatkan kemiskinan di perdesaan dan perkotaan. Berdasarkan data dari BPS, jumlan penduduk miskin meningkat dari 22,5 juta atau 11 persen terhadap total penduduk sebelum krisis. (tahun 1996) menjadi 49,4 juta alau 24 persen pada puncak krisis (tahun 1998). Dengan berbagai upaya program penanggulangan kemiskinan yang dilakukan, jumlah penduduk miskin u run menjadi 37,5 juta (18 persen) pada Agustus 1999 dan diperkirakan menjadi 32,8juta (16 persen) pada Februari 2000 (Kedaulatan Rakyat. 2001).

Menu ru: Coleman dan Cressey (1987) dalam 50 tahun terakhir kemiskinan dipandang sebagai masalah institusional daripada masalah personal. Di perkotaan, dilaksanakan suatu program penanggulangan kemiskinan yang disebut Proyek Penanggulangan Kemiskinan di Perkotaan (P2KP). Tujuan P2KP adalah membiayai 
kegiatan-kegiatan yang dapat memberi manfaat kepada masyarakat miskin di kelurahan sasaran, melalui (1) Bantuan modal kerja bergulir bagi upaya peningkatan pendapatan secara berkelanjutan (2) Hibah bagi pembangunan/perbaikan prasarana dan sarana dasar lingkungan.

P2KP menganut pendekatan pemberdayaan sebagai suatu syarat menuju pembangunan yang berkelanjutan. Hal ini sesuai dengan paradigma baru dalam penanggulangan kemiskinan. Menurut HS Dillon selaku Kepala Badan Koordinasi Penanggulangan Kemiskinan (BKPK), tugas utama BKPK adalah mengembangkan diskursus setara untuk mendorong pernerintah pusat dan daerah, tokoh masyarakat, omop, perguruan tinggi, lembaga eksekutif dan legislatif untuk menerapkan paradigma baru yaitu saatnya menempatkan si miskin menjadi aktor untuk menanggulangi kemiskinannya sendiri (Kedaulatan Rakyat, 2001).

P2KP mengalokasikan dana untuk kelurahan berupa hibah bervaniasi menurut ukuran kelurahan. Untuk memastikan adanya keterbukaan di tingkat kelurahan, kepada masyarakat akan diumumkan jumlah maksimum bantuan per RW sekitar Rp $00.000,00$ dengan catatan tiap RW tidak dengan sendirinya akan mendapatkan seluruh dana dimaksud. Bagi kelurahan yang kemajuan pelaksanaannya rendah selama enam bulan pertama, hak mendapat bantuan dapat dialihkan ke keturahan lain. Tiap kelurahan akan mendapat bantuan satu kali selama proyek berjalan.

Dana dari P2KP dapat digunakan untuk kredit bagi kegiatan ekonomi berkelanjutan dan hibah untuk pembangunan/perbaikan prasarana dan sarana dasar lingkungan, tergantung pada prioritas kebutuhan kelompok-kelompok masyarakat setempat. Beberapa contoh kegiatan yang dapat dikembangkan adalah pertanian kota, pelatihan bagi kelompok produktif, pembelian alat-alat kerja (mesin jahit, komputer, dan lain-lain), atau pembangunan/ perbaikan perumahan bertumpu pada masyarakat yang masa pengerjaannya tidak lebih dari satu tahun.

Pada tahap pertama, lokasi sasaran P2KP terdiri dari 57 daerah tingkat (Dati) ॥ di wilayah utara, ditambah Daerah Istimewa Yogyakarta, Kabupaten dan Kota Bandung. serta Kabupaten dan Kota Malang. Wilayah ini dipilih karena merupakan kawasan perkotaan yang padat dengan jumlah penduduk miskin yang relatif besar. Di DIY terdapat 5 kelurahan sasaran di Kabupaten Kuion Progo, 13 kelurahan sasaran di Kabupaten Bantul, 9 kelurahan sasaran di Kabupaten Gunung Kidul, 12 kelurahan sasaran di Kabupaten Sleman, dan 14 kelurahan sasaran di Kotamadya Yogyakarta.

Kelurahan Pakuncen merupakan salah satu kelurahan yang diberi dana dalam pelaksanaan P2KP dengan alokasi dana pada Tahap I sebesar Rp 250.000.00. Kelurahan Pakuncen terletak di Kecamatan Wirobrajan, Kota Yogyakarta, Propinsi DIY dengan luas wilayah $64.933 \mathrm{Ha}$ yang di sebelah utara berbatasan dengan Kecamatan Tegalrejo, Kota Yogyakarta, di sebelah selatan berbatasan dengan Kelurahan Wirobrajan, Kota Yogyakarta, di sebelah barat berbatasan dengan Kelurahan Ngestiharjo, Kecamatan Kasihan. Kabupaten Bantul, dan di sebelah timur berbatasan dengan Kelurahan Ngampilan. Kota Yogyakarta. Penduduk di Kelurahan Pakuncen berjumlah 11.638 jiwa yang tersebar di 56 rukun tetangga (RT) dan 12 rukun warga (RW) (Data Monografi JuliDesember2000).

Sebagai prasyarat bagi pemberian bantuan kepada masyarakat miskin di kelurahan tersebut, maka dibentuk Badan Keswadayaan Masyarakat (BKM) Berkah Mulyo pada tanggal 13 Maret 2000 dengan 
akta pendirian nomer 04 tanggal 13 Maret 2001 dengan notaris Gelis Rahmat Joko Pradopo, SH, S.Sos. BKM Berkah Mulyo pada awainya berkantor di Kantor Kelurahan Pakuncen kalu pindah di Jl. Ngadimulyo No. 16,Pakuncen, Yogyakarta.

Perorangan dan keluarga miskin yang berdomisili di kelurahan tersebut didorong untuk menghimpun dirinya ke dalam suatu Kelompok Swadaya Masyarakat (KSM). KSM merupakan target penerima bantuan P2KP yang sesungguhnya. KSM penerima bantuan P2KP harus memenuhi beberapa persyaratan sebagai berikut (Buku Satu: Pedoman Umum, 1999):

1. Beranggotakan minimal 3 orang (dari rumah tangga yang berbeda).

2. Anggota berasal dari keluarga berpenghasilan rendah berdasarkan kesepakatan bersama antara lurah/kepala desa, tokoh masyarakat, pengurus RT/RW, dan warga masyarakat lainnya.

3. Jumlah anggota yang tidak berasal dan keluarga miskin (namun diajak bergabung karena memiliki ketrampian tertentu yang dibutuhkan), dibatasi tidak lebih dari sepertiga jumlah anggota KSM.

Perkembangan P2KP di Kelurahan Pakuncen menunjukkan perkembangan yang terus meningkat yang diturjukkan dengan jumlah KSM maupun bantuan modal kerja bergulir yang terus bertambah. Dana yang bergulir sampai dengan 21 Juni 2001 adalah Rip 438.250.000,00. Di samping itu selama pelaksanaan P2KP, BKM Berkah Mulyo telah mengumpulkan dana sejumlah Rp 22.000.000,00 dari bunga bantuan modal kerja bergulir anggota KSM.

Permasalahan yang timbul dalam pelaksanaan P2KP adalah masih terdapat anggota KSM yang belum lancar dalam mengembalikan bantuan modal kerja bergulir. Pengurus BKM Berkah Mulyo membagi pengembalian bantuan modal kerja bergulir dalam 3 kategori, yaitu lancar, kurang lancar, dan tidak lancar. Bantuan lancar adalah bantuan yang dapat dikembalikan tepat pada waktunya. Bantuan modal kerja bergulir yang kurang lancar berarti bantuan modal kerja bergulir tersebut dapat dikembalikan setelah dijadwal ulang, sedangkan bantuan modal kerja bergulir tidak lancar berarti tidak dapat dikembalikan namun tetap dilakukan penagihan. Jumlah dana yang tergolong dalam pengembalian bantuan modal kerja bergulir yang kurang lancar dan tidak lancar adalah Rp $20.000 .000,00$. Hal ini tentu saja menghambat upaya pengentasan kerniskinan karena dana tersebut merupakan bantuan modal kerja bergulir bagi upaya peningkatan pendapatan secara berkelanjutan, artinya bila terdapat anggota KSM yang kurang atau tidak lancar dalam mengembalikan bantuan modal kerja bergulinya maka akan ada masyarakat lain yang tertunda kesempatannya mendapat bantuan modal kerja.

Di sisi lain, keberadaan BKM bukanlah semata-mata lembaga keuangan untuk peminjaman uang seperti bank pada umumnya tetapi merupakan lembaga yang dirancang untuk membangun kembali kehidupan masyarakat mandiri yang mampu mengatasi kemiskinannya atau dengan kata lain mengemban misi pemberdayaan. Oleh sebab itu bila terdapat kekuranglancaran dalam pengembalian bantuan modal kerja bergulir berarti usaha pemberdayaan masyarakat tidak dapat dilaksanakan dengan optimal.

Permasalahan kurang lancarnya pengembalian bantuan modal kerja bergulir dapat dianalisisis dengan melihat peran pihak-pihak yang terkait (stakeholders) dalam P2KP, yaitu KSM, BKM, masyarakat, aparat RT. RW, dan kelurahan, dan fasilitator kelırahan. Hubungan peran antar pihak-pihak terkait, pengaruh peran suatu 
pihak terhadap pihak lain, serta kepentingan dasar dari pihak-pihak tersebut-memiliki dinamika sosial tersendiri. Hal ini disebabkan pelaksanaan P2KP membentuk suatu struktur sosial yang memiliki dinamika tertentu. Dinamika sosial ini mempengaruhi perilaku pihak-pihak terkait berdasar peran yang dimilikinya, termasuk perilaku-perilaku yang berkaitan dengan pengembalian bantuan modal kerja bergulir. Permasalahan kekuranglancaran pengembalian bantuan modal kerja bergulir perlu dianalisis lebih lanju: untuk mengembangkan rancangan penyelesaian yang jelas dan realistis dengan mel hat dinamika sosial yang terjadi dan berdasarkan peran dari pihak-pihak terkait.

\section{TELAAH PUSTAKA}

\section{Peran dalam Suatu Sistem Soslal}

Kehidupan manusia dalam suału sistem sosial mempunyai konsekuensi tertentu, yaitu keberadaan seseorang dalam kelompoknya. Hal ini membuat perilakunya tidak berdiri sendiri tetapi berkaitan dengan peran yang dimainkan dan kehadiran orang lain yang berhubungan dengan peran tersebut. Michener (dalam Michener dan DeLamater, 1999) menyatakan bahwa peran adalah seperangkat fungsi yang dibentuk anggota untuk kelompoknya. Fungsi tersebut berbentuk perilaku yang dikarakteriștikkan melalui pengenalan kembali seseorang dalam konteks tertentu. Konsep dari Teori Peran mempelajari perilaku yang dicirikan dari orang yang "beraksi", sehingga disebut aktor, dengan peran tertentu dalam sistem sosiai tertentu.

Preposisi dalam Teori Peran adalah sebagai berikut (Michener dan DeLamater, 1999):

1. Manusia menghabiskan banyak waktu dalam hidupnya dengan berpartisipasi sebagai anggota kelompok dan organisasi.

2. Dalam kelompok tersebut, manusia menduduki posisi-posisi yang berbeda.

3. Setiap posisi-posisi tersebut memerlukan suatu peran, yaitu seperangkat fungsi yang dikerjakan oleh seseorang untuk kelompoknya. Peran seseorang dibentuk oleh harapan-harapan (yang berasal dari anggota yang lain dari kelompok) yang mengarahkan perilaku orang tersebut.

4. Kelompok-kelompok sering memformalkan harapan-harapan ini sebagai norma, di mana peraturan-peraturan tentang bagaimana seseorang seharusnya berperilaku, keuntungan yang akan diperoleh bila berperilaku yang sesuai dengan norma, dan hukuman yang akan diterima bila melakukan berperilaku yang sesuai dengan norma.

5. Jika seseorang bertemu dengan harapanharapan dari orang lain, lalu dia akan menerima penghargaan dalam beberapa bentuk (penerimaan, persetujuan, uang, dan sebagainya). Jika dia gagal berperilaku sesuai dengan yang diharapkan, anggota kelompok akan mempermalukan, menghukum, atau bahkan mengeluarkan individu dari kelompok. Linton (dalam Stepan dan Stepan, 1985) membagi peran menjadi 2 tipe, yaitu peran yang diusahakan dan peran yang langsung diperoleh. Peran yang diusahakan memerlukan kemampuan atau pelatihan tertentu. misalnya guru, ketua, dan sebagainya. Peran yang langsung diperoleh biasanya berhubungan dengan peran seksual, misalnya anak perempuan, sepupu dan sebagainya.

Michener (dalam Michener dan DeLamater, 1999) menyatakan bahwa peran bukan hanya seperangkat aturan-aturan 
yang berfungsi sebagai suatu kerangka acuan dan panduan dalam berperilaku, tetapi juga menunjukkark tujuar-tujuan yang akan dicapai, tugas-tugas yang harus dilakukan, dan kinerja yang harus ditunjukkark.

Biddle dan Thomas (dalam Shaw dan Costanzo, 1982) menyatakan bahwa terdapat 5 konsep yang berhubungan dergan perilaku dalarn Teori Peran yaitu:

1. Harapan, yaitu harapan-harapan orang lain pada umumnya tentang perilaku yang pantas yang ditunjukkan oleh seseorang yang mempunyai peran tertentu.

2. Norrna, yaitu salah satu bentuk harapan yarıg bersifat meramalkan dan harapan normatif (Secord dan Backmark dalam Shaw dan Costanzo, 1982). Harapan rormatif dikelompokkan merijadi haraparı yang terselubung darı harapan yang terbuka.

3. Wujud perilaku. Wujud perilaku dari perarı dapat ditinjau dari intensitasnya. Tingkat terendah adalah di mana aktor sangat tidak terlibat sedang tingkat tertinggi apabila aktor melibatkan seluruh pribadirya, sedangkan intensitasnya dapat dinyatakark dengarı tirıkat permukaan dan tirıkat yang tidak sampai permukaart.

4. Penilaiar dan sanksi. Penilaian dan sanksi agak sulit untuk dibedakan. Penilaiarı dan sanksi didasarkan pada harapan masyarakat terhadap norma yang berlaku. Kesan postif dan negatif terhadap norma disebut penilaian, dan usaha orang untuk mempertahankan riıai positif dan regatif disebut sanksi.

\section{Peran dan Perubahan Perilaku}

Menurut Myers (1990). Teori Peran merlekankan pada perilaku peran dan perubahan sikap yang merupakan hasil dari penerapark peran-perark. Peran seseorang tidak hanya menentukan perilaku tetapi juga kepercayaan dan sikap. Teori Peran berasumsi bahwa manusia pada umumrlya konformis. Masyarakat berperilaku sesuai derigan harapars-harapan peran yang diadakan oleh anggota kelompok. Waiau demikiar, haraparı dari orarı lairı biasarya memberi ruarı untuk memperbaiki perilaku sehingga dapat disimpulkan bahwa masyarakat adalah pernbuat peran-peran yang membentuk mereka dan tidak sekedar terjadi konformitas yang pasif terhadap harapan-harapan.

Untuk mengubah perilaku seseorang, maka harus mengubah peran yang dimiliki. Perubahan perilaku akarl tampak jika seseorang bertukar peran karena peran yang baru memerlukan perbedaan harapan dan permintaan (Michener dan DeLamater. 1999). Berperan yang lairk dapat pula dilakukan dengan pengambilan perark, yaitu proses yang secara imajinatif menduduki posisi orang lain dan memandang diri dan bentuk-bentuk situasi sesuai dengan perspektif peran tersebut (Hewitt dalam Shawdan Costanzo, 1982).

Cara lain untuk mengubah perilaku seseorang adalah mengubah atau menegaskan kembali peranrya. Hal ini dapat dilakukan degan mengubah harapanharapan dari perannya atau memindahkan orang tersebut dalarn peran yang berbeda (Allen dan Van de Viert dalam Michener dan DeLamater, 1999).

\section{Kelompok Swadaya Masyarakat}

Kelompok Swadaya Masyarakat adalah satu kesatuan anggota dan persatuan para anggota. KSM merupakan milik anggota dan dimaksudkan urıtuk mengatasi masalah bersama dari para anggota dan merigembangkan usaha-usaha bersama dari masing-masirng arkggotarya. Dengan bergabung dalam KSM, masing-masing arıggota diharapkan dapat menggalang polensi diri, baik berupa uang, pikiran, cita- 
cita maupun tenaga (Hidayat dalam Ramdhani, 1996).

KSM hampir sama dengan self-help group. Napier dan dan Gershenfield dalam Ramdhani (1996) mengemukakan bahwa self-help group adalah kelompok sukarela yang berkumpu! untuk tukar menukar pengalaman tentang kebutuhan mereka dan masalah yang dihadapi. Biasanya self-helo group ini terdiri dari orang-orang yang merasa tidak berdaya karena mengalami kesulitan keuangan, menderita penyakit yang sulit bahkan belum bisa disembuhkan, dan sebab-sebab lain yang dapat menyebabkan ketidakberdayaan.

Menurut Yalom (dalam Ramdhani, 1996), individu dalam kelompoknya dapat merasakan universalitas. Dalam diri masingmasing anggota timbul kesadaran bahwa yang mengalami kekurangan bukan hanya mereka sendiri. Ada orang lain juga yang mengalami hal serupa. Perasaan menjadi "kecil" sebagai akibat himpitan ekonomi sebagai masyarakat miskin, sedikit demi sedikit berkurang, karena ternyata masih ada orang tain dengan keadaan sama. Dalam kelompok, individu dapat menjadi berani berbuat, karena ada perasaan sama rasa di antara anggotanya. Dalam kelompok, juga terdapat tukar menukar pengalaman atau sharingmengenai kiat-kiat mengatasi masalah yang biasanya menjadi fokus self thelp group.

\section{METODE PENELITIAN}

Metode penelitian yang digunakan dalam penelitian ini adalah metode kualitatif. untuk menganalisis permasaiahan digunakan metode ZOPP (Ziel Orientierte Project Planung = Perencanaan Proyek Beorientasi pada Tujuan),atau GOPP (Goal Oriented Project Planning) atau Perencanaan Proyek Beorientasi pada Tujuan. Metode ini dikenal sebagai metode perencanaan sejak tahap mendeskripsikan gejala sampai dengan pelaksanaan progam intervensi (Sucipto, 1999). Pendekatan ini memberikan cara yang sistematik untuk mengidentifikasi, merencanakan, dan mengatur pelaksanaan proyek dengan memperhatikan kepentingan pihak-pihak terkait (httg: / Www mit.edu, 2001). adalah:

Alat-alat kelengkapan metode ZOPP

1. Analisis Keadaan, yang terdiri dari:

a. Analisis Permasalahan, yang bertujuan untuk memilih satu masalah inti dan menunjukkan sernua hubungan sebab-akibat yang berkaitan dengan masalah inti tersebut.

b. Analisis Tujuan, yang bertujuan untuk menentukan keadaan yang diinginkan (tujuan) dan menunjukkan hubungan tindakan-hasil yang utama dan langsung.

c. Analisis Alternatif, yang bertujuan menelaah dan memiith beberapa altematif tindakan intervensi (proyek) dengan menggunakan kriteria tertentu.

d. Analisis Peran, yang bertujuan menelaah peran dari pihak-plhak yang terkait dalam hubungannya dengan pelaksanaan intervensi.

2. Rancangan Proyek, yang bertujuan merumuskan hal-hal yang berkaitan dengan rancangan intervensi yang akan dilakukan, meliputi tujuan, maksud dan sasaran, asumsi-asumsi penting. indikator objektif sekaligus sumber pembuktiannya, kegiatan, sarana dan biaya yang diperlukan.

Sucipto (1999), mengungkapkan bahwa penerapan ZOPP sebagai metode untuk menganalisis suatu permasalahan dapat berguna untuk:

1. Meningkatkan komunikasi dan kerjasama di antara pihak-pihak yang 
berkait melalui perencanaan bersama dan dokumentasi semua tahap perencanaan.

2. Mencapai pengertian yang sama dan menghasilkan definisi yang jelas mengenai keadaan yang ingin diperbaiki dengan proyek.

3. Merumuskan definisi yang jelas dan realistis tentang tindakan-tindakan yang diperlukan untuk mencapai tujuan-tujuan yang diinginkan.

4. Menghasilkan rencana proyek sebagai landasan keriasama untuk pelaksanaan, pengendalian, dan evaluasi proyek.

\section{HASIL PENELITIAN}

Penyusunan Analisis Permasalahan, Analisis Tujuan dilaksanakan dengan melibatkan Pengurus BKM, Fasilitator Kelurahan, dan KSM, sedangkan penulis bertindak sebagai fasilitator. Hasi\} dari analisis tersebut adalah sebagai berikut:

\section{Analisis Peran.}

Hasil dari Analisis Peran adalah sebagai berikut:

\begin{tabular}{|c|c|c|}
\hline $\begin{array}{l}\text { Nama Lembaga/ } \\
\text { Kelompok } \\
\text { dan Jenis Peran }\end{array}$ & Kemampuan & Kelemahan \\
\hline $\begin{array}{l}\text { KSM sebagai penerima } \\
\text { maniaat. }\end{array}$ & $\begin{array}{l}\text { 1. Mempurlyai jumlah anggota dan } \\
\text { kelompok yang banyak dan } \\
\text { tersebar d semua wilayah. } \\
\text { 2. Terdapal KSM yang polensial } \\
\text { unluk berkembang. } \\
\text { 3. Anggota KSM mempunyai } \\
\text { akses komunikasi yang baik } \\
\text { karena berada di wilayah kota. }\end{array}$ & $\begin{array}{l}\text { 1. Model KSM masih individual. } \\
\text { 2. Konsep P2KP belum dipanami } \\
\text { dengan baik. } \\
\text { 3. Kelembagaan KSM belum } \\
\text { berfungsi. }\end{array}$ \\
\hline $\begin{array}{l}\text { BKM sebagal rembaga } \\
\text { pelaksana. }\end{array}$ & $\begin{array}{l}\text { 7. Pengurus mengetahui dengan } \\
\text { baik kondist wilayah dan } \\
\text { warganya. } \\
\text { 2. Konsep-konsep pengembang. } \\
\text { an telah disiapkan oleh Ketua } \\
\text { dan Fasilitakor Kelurahan. }\end{array}$ & $\begin{array}{l}\text { 1. Sistem dalam organisasi belum } \\
\text { berjalan, } \\
\text { 2. Pemahaman tehadap P2KP dan } \\
\text { kemampuan personil pengurus } \\
\text { yang tidak merata. }\end{array}$ \\
\hline $\begin{array}{l}\text { Fasılitator kelurahan } \\
\text { sebagal mitra proyek. }\end{array}$ & $\begin{array}{l}\text { 1. Menuniukkan kinerja yang lebih } \\
\text { baik daripada fasilitator } \\
\text { sebelumnya. } \\
\text { 2. Mempunyai dedikasi yang baik } \\
\text { untuk mengembangkan kinerta } \\
\text { BKM. }\end{array}$ & $\begin{array}{l}\text { 1. Belum melakukan transfer kepada } \\
\text { kader masyarakal. }\end{array}$ \\
\hline $\begin{array}{l}\text { Masyarakal sebagai mitra } \\
\text { proyek dan penerima } \\
\text { manfaal. }\end{array}$ & $\begin{array}{l}\text { 1. Antusiasme yang tingg untuk } \\
\text { memperoleh bantuan modal } \\
\text { keria bergulir. } \\
\text { 2. Merupakan masyarakat } \\
\text { perkotaan yang mempunyai } \\
\text { potensi unituk memberikan } \\
\text { pengawasan sistemik. }\end{array}$ & $\begin{array}{l}\text { 1. Belum memahami konsep P2KP. } \\
2 \text { Tingkal kepeduliannya masih } \\
\text { rendah. }\end{array}$ \\
\hline
\end{tabular}




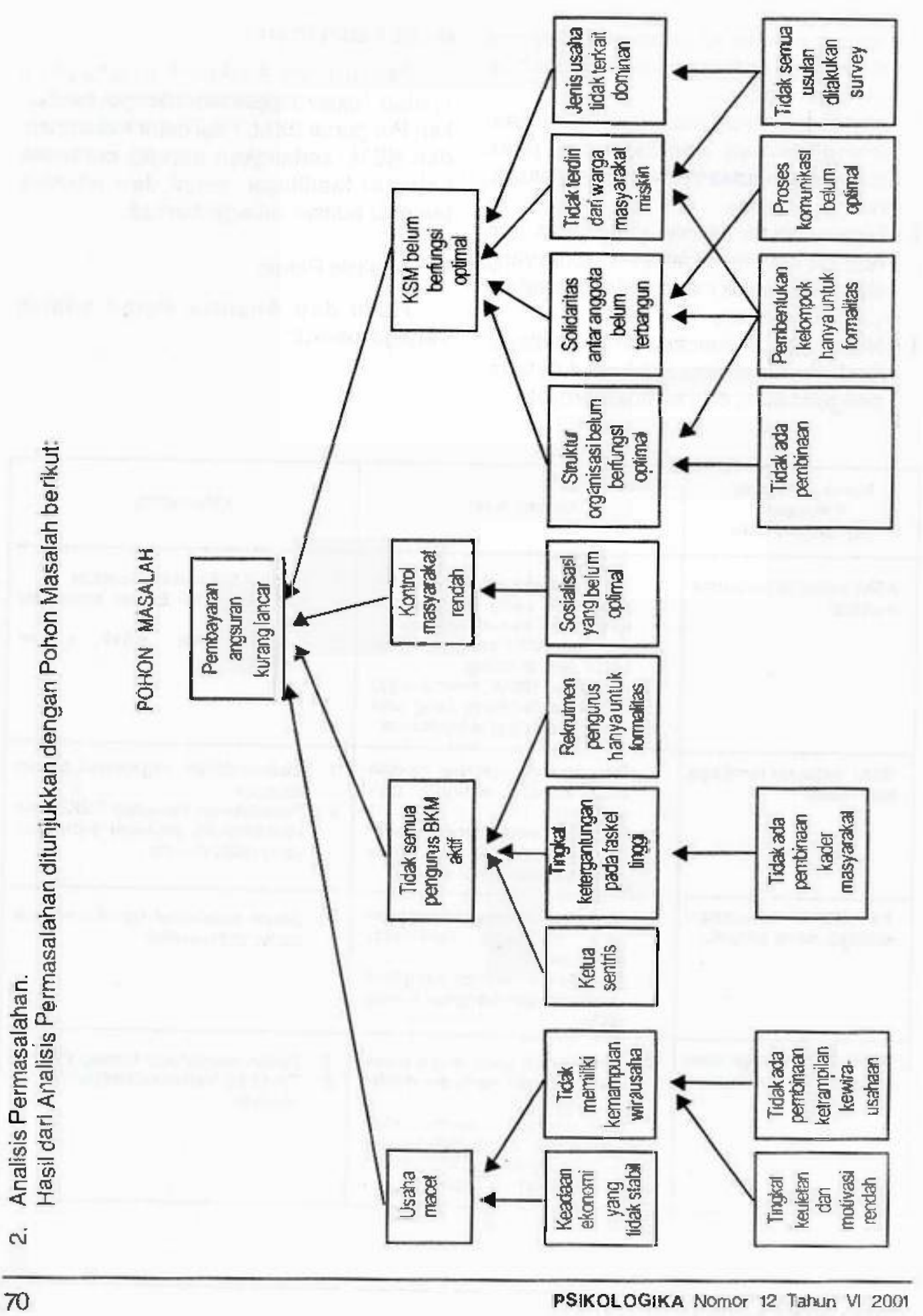




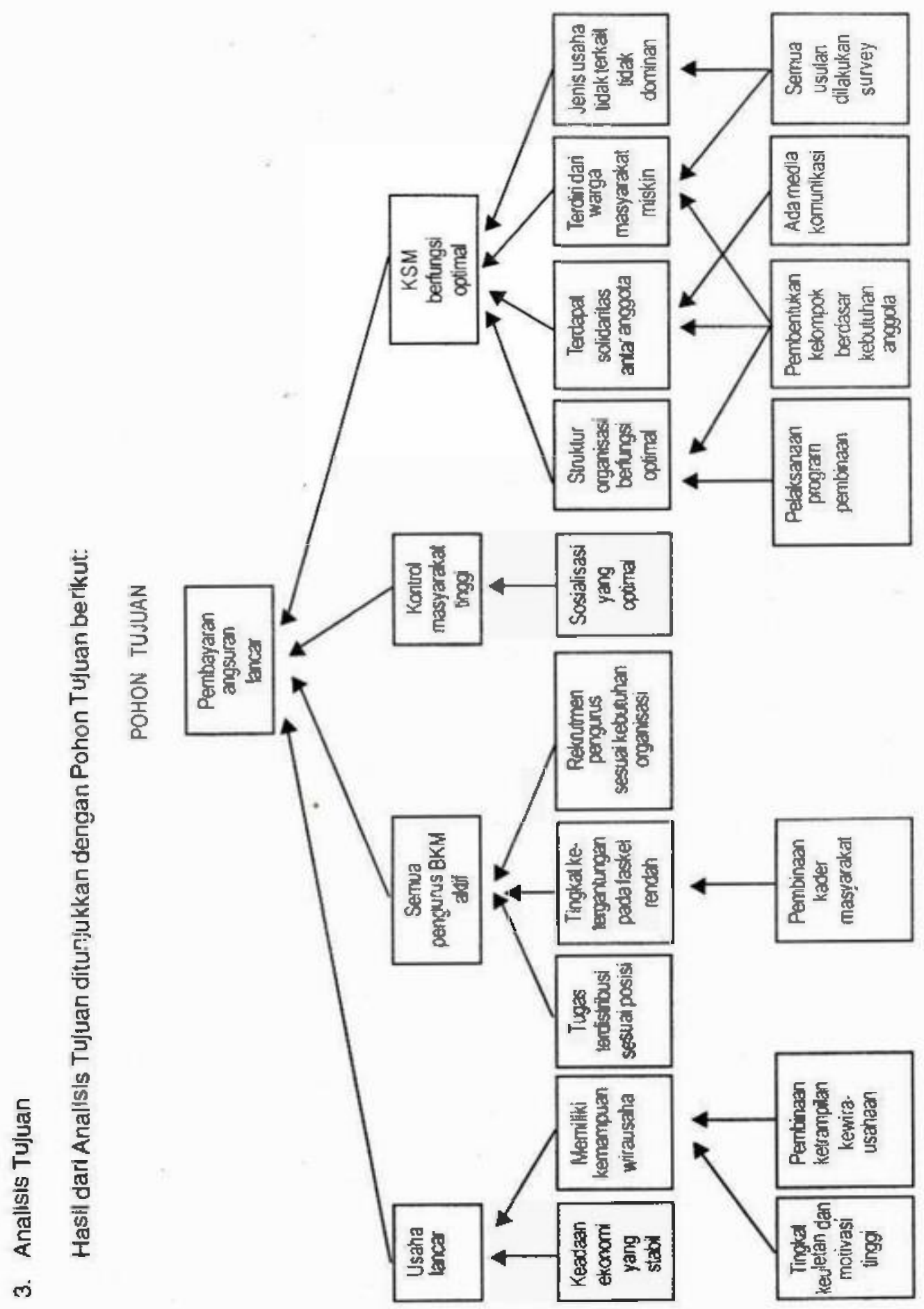


Berdasarkan Analisis Masalah dan Analisis Tujuan, kekuranglancaran pengembalian bantuan modal kerja bergulir oleh KSM di BKM Berkah Mulyo merupakan suatu dinamika sosial yang melibatkan 3 faktor yaitu faktor situasional, ins titusional, dan individual. Faktor situasional yang mempengaruhi adalah faktor kondisi perekonomian yang tidak menentu. Faktor institusional yang mempengaruhl adalah KSM, BKM, Fasilitator Kelurahan, dan masyarakat. Faktor individual yang mempengaruhi adalah kondisi anggota KSM. Faktortaktor tersebut tidak berdiri sendiri tetapi mempunyai hubungan saling mempengaruhi.

Faktor situasional berupa kondisi perekonomian yang tidak dapat diprediksi menyebabkan usaha produktif para anggota KSM tidak dapat dilanjutkan lagi. Di sisi lain, faktor individual anggota KSM khususnya kemampuan wirausaha dari anggota KSM yang masih perlu terus ditingkatkan. Ketrampilan wirausaha yang rendah tersebut disebabkan tingkat keuletan dan motivasi yang rendah, dan dipengaruhi faktor institusional yaitu tidak ada pembinaan dari BKM, khususnya Pokja Penguatan Kelembagaan KSM.

Pengembalian bantuan modal kerja bergulir yang kurang lancar juga disebabkan tidak semua pengurus BKM yang tersusun dalam strukturorgniasasi aktit menjalankan perannya dengan optimal sesuai dengan deskripsi kerjanya. Faktor institusional ini dapat disebabkan tugas-tugas organisasi sebagian besar dilaksanakan oleh ketua (Ketua sentris), tingkat ketergantungan pada faskel yang tinggi, dan perekrutan perıurus yang bertujuan untuk memenuhi persyaratan agar proses pembentukan BKM dapat dikaksanakan. Ketergantungan pada faskel tinggi disebabkan oleh belum adanya pembinaan kader masyarakat sehingga nantinya peran faskel dapat digantikan oleh kader masyarakat tersebut.
Tingkat kepeduliaan masyarakat terhadap Program P2KP, baik visi, misi, aktivitas, maupun dengan aktivitas organisasional dari lembaga yang berkaitan dengan P2KP dapat digolongkan rendah. Hal ini utamanya disebabkan dengan proses sosialisasi yang belum optimal, baik kuantitas maupun kualitas. Masyarakat belum dapat berperan sebagai fungsi kontrol sosial dengan menjalankan pengawasan secara sistemik.

Institusi lain yang belum menjalankan perannya dengan baik adalah Kelompok Swadaya Masyarakat. Hal ini disebabkan oleh struktur organisasi KSM walaupun sudah ada tapi belum baik, kebersamaan yang belum terbangun, dan jenis usaha anggota KSM bersifat aneka usaha tidak terkait yang dominan.

Masalah struktur organisasi yang belum berfungsi optimak berkaitan dengan tidak ada pembinaan dari BKM dan pembentukan kelompok sekedar untuk formalitas. Sebenarnya secara formal struktur KSM yang terdiri dari ketua dan anggota telah ada namun karena hanya untuk persyaratan administratif saja dan Pokja Penguatan Kelembagaan KSM tidak memberikan pembinaanlebih lanjut. Peran institusi KSM dan BKM sebenarnya memberikan kontribusi yang besar dalam faktor ini. Fasilitator Kelurahan dan BKM, khususnya Pokja Sosialisasi Kebijaksanaan BKM mempunyai peran yang signifikan.

Masalah kebersamaan anggota berkaitan dengan proses komunikasi yang belum optimal dan pembentukan kelompok untuk formalitas. Kebersamaan tidak dapat terbangun karena komunikasi hanya terladi ketika sosialisasi dan proses pencairan bantuan modal kerja. Setelah itu komunikasi dilakukan dengan media buletin. Hal ini tentu saja belum cukup untuk membangun kebersamaan atau dalam P2KP diterapkan dalam prinsip tanggung renteng. 
Masalah komposisi anggota berkaitan dengan proses pembentukan kelompok untuk formalitas dan tidak semua usulan dilakukan survey. Hal ini terlihat dalam kondisi ekonomi anggota KSM yang sebenarnya tidak termasuk dalam kategon Keluarga Pra Sejahtera dan Sejahtera I tapi sebenarnya telah layak unfuk mengajukan pinjarnan ke lemabaga perbankan (bankable).

Masalah jenis usaha tidak terkait yang dominan berkaitan dengan tidak semua usulan dilakukan survey. Bila dilakukan survey chpat membantu mengarahkan KSM agar kelompok yang individual, karena jenis usaha tidak terkait, diubah komposisi keanggotaan agar kelompok yang jenis usahanya berkaitan dapat bergabung dalam satu kelompok. Pelaksanaan survey merupakan salah peran yang harus dilaksanakan oleh Fasilitator Kelurahan dan Ketua BKM.

\section{PEMBAHASAN}

Dinamika sosial yang teriadi dalam permasalahan kekuranglancaran pengembalian bantuan modal kerja bergulir oleh KSM di BKM Berkah Mulyo dapal dianalisis dari peran-peran yang dimainkan oleh pihakpihak yang terkait. Sebagaimana disebutkan dalam preposisi dalam Teori Peran (Michener dan DeLamater, 1999) bahwa dalam kehidupan sosialnya manusia menduduki posisi-posisi tertentu yang memerlukan suatu peran. Kehidupan sosial yang dibentuk dalam pelaksanaan P2KP menyebabkan orang-orang yang berkecimpung di dalamnya menempati posisi-posisi tertentu yang memerlukan peran-peran tertentu pula.

Peran sebagai anggota KSM, KSM, BKM, Fasilitator Kelurahan, dan masyarakat memberikan suatu kerangka acuan dan panduan dalam berperilaku bahkan menunjukkan tujuan-tujuan yang akan dioapai, tugas-tugas yang harus dilakukan, dan kinerja yang harus ditunjukkan (Michener dalam Michener dan DeLamater. 1999). Peran sebagai KSM, misalnya. mengharuskan berperitaku mampu berwirausaha, mampu mengembalikan bantuan modal kerja tepat waktu, dapat bekerjasama dengan anggota yang lain, dan sebagainya. Keharusan beperilaku tersebut merupakan harapan-harapan orang lain tentang perilaku yang pantas ditunjukkan oleh seseorang atau kelompok yang mempunyai peran tertentu (Biddle dan Thomas dalam Shaw dan Costanzo, 1982). Harapan-harapan dalam konteks permasalahan pengembalian bantuan modal kerja bergulir dapat dicermati lebih lanjut dalam Analisis Tujuan yang menghasilkan Pohon Tujuan.

Suatu peran menunjukkan wujud perilaku dalam intensitas tertentu, apakah orang atau kelompok tersebut tertibat secara penuh atau tidak. Bila wujud perilakunya sesuai dengan harapan yang diinginkan maka dia akan menerima penghargaan tetapi bila gagaı maka akan menerima hukuman (Michenerdan DeLamater, 1999). Peran BKM, sebagai contoh, mengharuskan perilaku yang sesuai dengan yang diharapkan, misalnya melakukan monitoring, komunikasi dengan KSM, mengadakan pelatihan, sosialisasi kepada masyarakal, dan sebagainya. Bila yang berangkutan dapat berperilaku seperti harapan tersebut maka akan menerima penghargaan misaknya uang insentif, dinyatakan pengurus yang aktif, berjasa mengentaskan kemiskinan, dan sebagainya tetapi bila gagal maka akan menerima hukuman misalnya menjadi penyebab KSM tidak berkembang, tidak mendapat uang insentif, ditegur oleh Ketua BKM, dan sebagainya.

Kegagalan dalam berperilaku dilakukan pihak-pihak terkait seperti yang diharapkan menyebabkan pengembalian angsuran yang kurang lancar. Hal ini dapat dicermati dari 
Pohon Masalah. Oleh sebab itu, perlu dilakukan intervensi dengan 2 cara yaitu nengubah perannya dan menegaskan kembali perannya. Mengubah peran dapat dilakukan dengan bertukar peran karena peran yang baru mempunyai harapan yang lain pula (Michenerdan DeLamater, 1999) atau melakukan pengambilan peran yaitu secara imajinatif menduduki peran yang lain (Hewitt dalam Shaw dan Costanzo, 1982). Menegaskan kembali perannya dilakukan dengan menegaskan harapan-harapan sehingga diharapkan dia akan mengubah perilakunya (Allen dan Van de Viert dalam Micehenerdan DeLamater, 1999).

Dua intervensi seperti tersebut di atas dapat dilaksanakan dengan berdasar pada Pohon Tujuan karena Pohon Tujuan merupakan harapan-harapan terhadap perilaku masing-masing peran. Mengubah peran dari individu atau kelompok yang terkait diharapkan akan melancarkan pengembalian moda! kerja bergulir. Hal ini disebabkan dengan harapan-harapan yang baru, muncui penlaku-perilaku baru yang sesuai dengan harapan yang baru pula, misalnya Pengurus di suatu Pokja perlu dimutasi ke Pokja yang lain yang lebih sesuai. Di samping itu. menegaskan kembali peran dari individu atau kelompok dapat pula dilakukan karena hal itu akan memberikan arahan bahwa perilakunya selama ini tidak sesuai dengan yang seharusnya dan harus mengubahnya sesuai dengan yang diharapkan, misalnya anggota KSM yang usahanya macet karena tidak memiliki kemampuan wirausaha maka dari EKM diharuskan melakukan pembinaan ketrampilan kewirausahaan dan dari anggota KSM harus menunjukan keuletan dan motivasi yang tinggi.

Setelah diperoleh Pohon Tujuan sebagai hasil dari anaisis untuk menentukan keadaan yang diinginkan dan menunjukkan hubungan tindakan-hasii yang utama dan langsung, maka disusun Analisis Alternatif dan Rancangan yanghasilnya sebagai berikut:

\section{Anaiisis Alternatif}

Pemilihan intervensi yang tepat untuk mengatasi masalah kekuranglancaran pengembalian bantuan modal kerja bergulir diłakukan dengan Analisis Alternatif. Hasit analisis adalah sebagai berikut: 


\begin{tabular}{|c|c|c|c|c|c|c|c|c|c|}
\hline \multirow[b]{2}{*}{ No } & \multirow[b]{2}{*}{$\begin{array}{l}\text { Alternatlf } \\
\text { Intervensi }\end{array}$} & \multicolumn{7}{|c|}{ Kriteria } & \multirow{2}{*}{$\begin{array}{l}T \\
O \\
T \\
A \\
L\end{array}$} \\
\hline & & $\begin{array}{l}\text { Sarana } \\
\text { yang } \\
\text { tersedia }\end{array}$ & $\begin{array}{c}\text { Waktu } \\
\text { yang } \\
\text { lersedia }\end{array}$ & $\begin{array}{l}\text { Peluang } \\
\text { keber- } \\
\text { hasilan }\end{array}$ & $\begin{array}{c}\text { Sumbang } \\
\text { an unluk } \\
\text { us ana } \\
\text { lain }\end{array}$ & $\begin{array}{c}\text { Kesinam- } \\
\text { bungan }\end{array}$ & $\begin{array}{c}\text { Dampak } \\
\text { lerhadap } \\
\text { lingkungan }\end{array}$ & $\begin{array}{c}\text { Perbandingan } \\
\text { keuntungan- } \\
\text { biaya }\end{array}$ & \\
\hline 1 & $\begin{array}{l}\text { Sosialisasi } \\
\text { kepada } \\
\text { masyarakat }\end{array}$ & 4 & 5 & 3 & 4 & 4 & 5 & 4 & 29 \\
\hline 2 & $\begin{array}{l}\text { Pertemuan } \\
\text { KSM dengan } \\
\text { BKM }\end{array}$ & 4 & 2 & 2 & 4 & 3 & 5 & 2 & 22 \\
\hline 3 & $\begin{array}{l}\text { Perbaikan } \\
\text { susunan } \\
\text { pengurus }\end{array}$ & 4 & 2 & 3 & 5 & 4 & 5 & 5 & 29 \\
\hline 4 & $\begin{array}{l}\text { Pelatihan } \\
\text { motivasi dan } \\
\text { ketrampilan } \\
\text { wirausaka }\end{array}$ & 4 & 4 & 4 & 4 & 5 & 5 & 3 & 29 \\
\hline 5 & $\begin{array}{l}\text { Survey d } \\
\text { KSM yang } \\
\text { mengajukan } \\
\text { permohonan } \\
\text { bantuan } \\
\text { modal keria }\end{array}$ & 5 & 5 & 5 & 5 & 5 & 5 & 5 & 35 \\
\hline 6 & $\begin{array}{l}\text { Persyaratan } \\
\text { wajb } \\
\text { mengikuti } \\
\text { pelatihan bagi } \\
\text { KSM yang } \\
\text { mengajukan } \\
\text { permohonan } \\
\text { banuan } \\
\text { modal kerja }\end{array}$ & 4 & 3 & 4 & 5 & 5 & 5 & 3 & 29 \\
\hline 7 & $\begin{array}{l}\text { Pembinaan } \\
\text { kader } \\
\text { masyarakat }\end{array}$ & 4 & 1 & 2 & 5 & 2 & 5 & 5 & 24 \\
\hline
\end{tabular}


hterval skor untuk kriteria adalah 1 sampai dengan 5. Nilai 1 menunjukkan bahwa kriteria tersebut sangat tidak layak untuk pelaksanaan intervensi dan nilai $5 \mathrm{me}$ nunjukkan bahwa kriteria tersebut sangat layak untuk pelaksanaan intervensi. Intervensi yang dipilih tninimal mempunyai total nilai 28 dan semakin tinggi total nilai tnaka intervensi tersebut menjadi prioritas untuk dilaksanakan terlebih dahulu. Berdasar analisis d atas dapat disimpulkan bahwa intervensi yang dapat dilakukan adalah:
1. Survey di KSM yang mengajukan permohonan bantuan ınodal kerja.

2. Sosialisasi kepada ınasyarakat.

3. Pelatihan motivasi dan ketraınpilan wirausaha.

4. Persyaratan wajib mengikuti pelatihan bagi KSM yang mengajukan permohonan bantuan modal kerịa.

5. Perbaikan susunan pengurus.

4. Pancangan Proyek

Pelaksaan intervensi, yang telah ditentukan sebagai hasil dari Analisis Alternatif, dilaksanakan dengan menggunakan matriks perencanaan proyek sebagai berikut: 


\section{MATRIKS PERENCANAAN PROYEK 1}

NAMA PROYEK : Survey awal

JANGKA WAKTU: 2 harl tiap KSM

\begin{tabular}{|c|c|c|c|}
\hline $\begin{array}{l}\text { TUIUAN-TUJUAN } \\
\text { DAN KEGIATAN- } \\
\text { KEGIATAN PROYEK: } \\
\text { Mengoptimalkan fungsi } \\
\text { KSM }\end{array}$ & $\begin{array}{l}\text { INDIKATOR-INDIKATOR } \\
\text { OBJEKTIF: } \\
\text { Setiap persetujuan per- } \\
\text { mohonan banluan modal } \\
\text { kerja tetah dilakukan sur- } \\
\text { vey terhadap anggota den } \\
\text { jenis usaha }\end{array}$ & $\begin{array}{l}\text { SUMBER-SUMBER } \\
\text { PEMBUKTIAN: } \\
\text { Daftar Usulan Kegialan } \\
\text { yang layak }\end{array}$ & $\begin{array}{l}\text { ASUMSI-ASUMSI } \\
\text { PENT ING: } \\
\text { Dukungan aparat AT } \\
\text { dan AW }\end{array}$ \\
\hline $\begin{array}{l}\text { SASARAN PROYEK: } \\
\text { KSM yang mengajukan } \\
\text { permohonan bantuan } \\
\text { modal kera }\end{array}$ & $\begin{array}{l}\text { Seliap permohonan } \\
\text { bantuan modal kerja telah } \\
\text { memberikan data yang } \\
\text { dibutuhkan }\end{array}$ & $\begin{array}{l}\text { Fommulir Usulan Keglatan } \\
\text { KSM dan Perhitungan } \\
\text { Kalayakan Keuangan } \\
\text { Usulan Keglatan Usaha } \\
\text { Produktif }\end{array}$ & $\begin{array}{l}\text { Pemahaman pengisian } \\
\text { formulir }\end{array}$ \\
\hline $\begin{array}{l}\text { MAKSUD PROYEK: } \\
\text { Mengupayakan agar } \\
\text { anggota terdiri dari } \\
\text { masyarakat miskin. } \\
\text { Jumlah jenis usaha } \\
\text { terkait tebih banyak }\end{array}$ & $\begin{array}{l}\text { Setiap pengajuan bantuan } \\
\text { modal kerja telah dibahas } \\
\text { kelayakannya }\end{array}$ & $\begin{array}{l}\text { Benta Acara Pembahas. } \\
\text { an Prioritas Usulan } \\
\text { Kegiatan }\end{array}$ & $\begin{array}{l}\text { Tidak ada intervensi } \\
\text { dart fuar dalam } \\
\text { pengambilan keputusan }\end{array}$ \\
\hline $\begin{array}{l}\text { HASIL-HASIL KERJA } \\
\text { PAOYEK: } \\
\text { Anggota KSM terdin dari } \\
\text { masyarakat miskin } \\
\text { Jenis uSaha terkait } \\
\text { dominan }\end{array}$ & $\begin{array}{l}\text { Settap KSM paling ban yak } \\
1 \text { orang yang bukan } \\
\text { masyarakat miskin }\end{array}$ & Daftar Anggota KSM & Kejujuran anggota KSM \\
\hline $\begin{array}{c}\text { KEGIATAN-KEGIATAN } \\
\text { PROYEK } \\
\text { Mengajukan pertanya- } \\
\text { a n-pertanyaan, Me- } \\
\text { ngecek ke tempat usana }\end{array}$ & $\begin{array}{l}\text { SAAAN DAN B } \\
\text { Formulir } \\
\text { Lang insentif } \\
\text { Fasiliator Kelurahan da } \\
\text { Hencane Kerja }\end{array}$ & $\begin{array}{l}\text { AYYA PAOYEK } \\
\text { POKja Monitoring dan }\end{array}$ & \\
\hline
\end{tabular}




\section{MATRIKS PERENCANAAN PROYEK 2}

NAMA PROYEK : Sosialisasi

JANGKA WAKTU : 3 hari

\begin{tabular}{|c|c|c|c|}
\hline $\begin{array}{l}\text { TU JUAN - TU JUAN } \\
\text { DAN KEGIATAN- } \\
\text { KEGIATAN PROYEK: } \\
\text { Meringka tkan pe- } \\
\text { mahamarı masyarakat } \\
\text { terhadap P2KP }\end{array}$ & $\begin{array}{l}\text { INDIKAT OR-INDIKATOR } \\
\text { OB.JEKTIF: } \\
\text { Terdapat persepsi positif } \\
\text { terhadap P2KP }\end{array}$ & $\begin{array}{l}\text { SUMBEF-SUMBER } \\
\text { PEMBUKTIAN: } \\
\text { Hasil wawancara }\end{array}$ & $\begin{array}{c}\text { ASUMSIASUMSI } \\
\text { PENTING: } \\
\text { Penerimaarı } \\
\text { masyarakat terhadap } \\
\text { proyek sosłalisasi }\end{array}$ \\
\hline $\begin{array}{l}\text { SASARAN PROYEK: } \\
\text { Masyarakat } \\
\text { Keluraharı Pakuncen }\end{array}$ & $\begin{array}{c}\text { Tercatat sebagai warga } \\
\text { Pakuncen }\end{array}$ & Daltar warga Pakuncen & $\begin{array}{l}\text { Dukungarı aparat RT } \\
\text { dan RN }\end{array}$ \\
\hline $\begin{array}{l}\text { MAKSUD PROYEK: } \\
\text { Memberikar pe- } \\
\text { mahaman terhadap } \\
\text { masyarakat tentang } \\
\text { peran vitai P2KP }\end{array}$ & $\begin{array}{l}\text { Masyarakal telah menerima } \\
\text { iriformasi dari P2KP dari } \\
\text { BKM }\end{array}$ & Telah diadakan sosialisasi & Dukurigan masyarakat \\
\hline $\begin{array}{l}\text { HASIL-HASIL KERJA } \\
\text { PROYEK: } \\
\text { Merlingkatkan perarı } \\
\text { masyarakat sebagai } \\
\text { furigsi kontrol }\end{array}$ & $\begin{array}{l}\text { Masyarakaf memberi } \\
\text { masukan tentang } \\
\text { peiaksanaan P2KP }\end{array}$ & $\begin{array}{l}\text { Saran atatu kritikarı } \\
\text { kepada } \mathrm{BKM}\end{array}$ & $\begin{array}{l}\text { Kesiapan masyarakat } \\
\text { daiam memberikarı sa- } \\
\text { ran dan kritk }\end{array}$ \\
\hline $\begin{array}{l}\text { KEGIATAN-KEGIATAN } \\
\text { PROYEK } \\
\text { Memberikan pe- } \\
\text { ryuithan kepada } \\
\text { masyarakat dalam } \\
\text { pertemuari-pertemuan } \\
\text { warga }\end{array}$ & \multicolumn{2}{|c|}{$\begin{array}{l}\text { SARAN DAN EAYA PHOYEK } \\
\text { Penyaji materi sosialisasi } \\
\text { Biaya konsumsi pertemuan } \\
\text { Tempal pertemuan } \\
\text { Bantuan pembangunan fisik }\end{array}$} & $\begin{array}{l}\text { Program dark lembaga } \\
\text { keuangan tingkat } \\
\text { keluraharı }\end{array}$ \\
\hline
\end{tabular}


MATRIKS PERENCANAAN PROYEK 3

NAMA PROYEK: Pelatihan Kewirausahaan

JANGKA WAKTU: 2 hari

\begin{tabular}{|c|c|c|c|}
\hline $\begin{array}{l}\text { TUJUAN-TUJUAN } \\
\text { DAN KEGIATAN- } \\
\text { KEGIATAN PROYEK: } \\
\text { Meningkatkan } \\
\text { ketrampilan } \\
\text { wirausaha }\end{array}$ & $\begin{array}{l}\text { INDIKATOR-INDIKATOR } \\
\text { OBJEKTIF: } \\
\text { Terdapat Lpaya } \\
\text { meningkatkan kualitas } \\
\text { berwirausaha }\end{array}$ & $\begin{array}{l}\text { SUMBER-SUMBEA } \\
\text { PEMBUKTIAN: } \\
\text { Laporan dari Pokja } \\
\text { Monitoring }\end{array}$ & $\begin{array}{l}\text { ASUMSI-ASUMS: } \\
\text { PENTING: }\end{array}$ \\
\hline $\begin{array}{l}\text { SASARAN PROYEK: } \\
\text { KSM d Berkah Mulyo }\end{array}$ & $\begin{array}{l}\text { Tercatat sebagai anggota } \\
\text { KSM di BKM Berkah Mulyo }\end{array}$ & $\begin{array}{l}\text { Daftar KSM o BKM } \\
\text { Berkah Mulyo }\end{array}$ & \\
\hline $\begin{array}{l}\text { MAKSUD PROYEK: } \\
\text { Memberikan ke- } \\
\text { mampuan untuk melihat } \\
\text { peluang usaha dan } \\
\text { adminisirasi kedangan }\end{array}$ & Mengikuti pelatihan & Daltar hadir & \\
\hline $\begin{array}{l}\text { HASIL-HASIL KERJA } \\
\text { PROYEK: } \\
\text { Mampu melihal peluang } \\
\text { Usaha dan melakukar } \\
\text { admisnilrasi kedangan } \\
\text { sederhane }\end{array}$ & $\begin{array}{l}\text { Menerapkan materi } \\
\text { pelatihan }\end{array}$ & $\begin{array}{l}\text { Laporan dari Pokja } \\
\text { Pengualan } \\
\text { Kelembagaan KSM }\end{array}$ & $\begin{array}{l}\text { Minat peserta untuk } \\
\text { menerapkan mater } \\
\text { pelatihan }\end{array}$ \\
\hline $\begin{array}{l}\text { KEGIATAN-KEGIATAN } \\
\text { PROYEK } \\
\text { Pelatihan tentang } \\
\text { Peluang Usaha dan } \\
\text { Administrasi Keuangan }\end{array}$ & \multicolumn{2}{|c|}{$\begin{array}{l}\text { SARAN DAN BIAYA PROYEK } \\
\text { Tempat pelatihan } \\
\text { Pemateri } \\
\text { konsumsi }\end{array}$} & $\begin{array}{l}\text { Kesulitan untuk } \\
\text { menentukan waktu } \\
\text { yang sesuai }\end{array}$ \\
\hline
\end{tabular}


MATRIKS PERENCANAAN PROYEK 4

NAMA PROYEK : Wajib pelatihan bagi KSM barU

JANGKA WAKTU : 1 hari

\begin{tabular}{|c|c|c|c|}
\hline $\begin{array}{l}\text { TUJUAN-TUUUAN DAN } \\
\text { KEGIATAN-KEGIATAN } \\
\text { PROYEK: } \\
\text { Membina KSM agar } \\
\text { dapat memanfaatkan } \\
\text { bantuan modal kerla }\end{array}$ & $\begin{array}{l}\text { INDIKATOR-INDIKATOR } \\
\text { OBJEKTIF: } \\
\text { Terdapat persyaratan } \\
\text { wajib mengikuti pelathan } \\
\text { bagi KSM baru }\end{array}$ & $\begin{array}{l}\text { SUMBEA. SU M BER } \\
\text { PEMBUKTIAN: } \\
\text { Prosedur Permohonan } \\
\text { Bantuan Modai Kerja }\end{array}$ & $\begin{array}{l}\text { A SUMSI- A SUMSI } \\
\text { PENTING: } \\
\text { Dorongan konsumtif }\end{array}$ \\
\hline $\begin{array}{l}\text { SASARAN PROYEK: } \\
\text { KSM barU }\end{array}$ & $\begin{array}{l}\text { Tercatal sebagal KSM } \\
\text { yang akan mengajukan } \\
\text { permohonan bantuan } \\
\text { modak kerja }\end{array}$ & $\begin{array}{l}\text { Rekapituiasi } \\
\text { Kegiatan KSM }\end{array}$ & \\
\hline $\begin{array}{l}\text { MAKSUO PROYEK: } \\
\text { Membenkan informasi } \\
\text { tentang vis dan misi } \\
\text { P2KP dan materi dasar } \\
\text { kewirausahaan }\end{array}$ & $\begin{array}{l}\text { Diaksanakan pelatihan } \\
\text { bagi KSM baru }\end{array}$ & $\begin{array}{l}\text { Laporan Pokja Penguatan } \\
\text { Keiembagaan KSM }\end{array}$ & \\
\hline $\begin{array}{l}\text { HASIL-HASIL KERJA } \\
\text { PAOYEK: } \\
\text { KSM baru memperoleh } \\
\text { informzasi yang benar } \\
\text { tentang P2KP dan } \\
\text { bimblngan berwira- } \\
\text { us aha }\end{array}$ & $\begin{array}{l}\text { Mempunyai rencana } \\
\text { daiam penggunaan } \\
\text { bantuan modai kera }\end{array}$ & $\begin{array}{l}\text { Laporan Fasilitator } \\
\text { Keiurahan }\end{array}$ & \\
\hline $\begin{array}{l}\text { KEGIATAN-KEGIATAN } \\
\text { PROYEK } \\
\text { Membenkan peiatihan } \\
\text { dan sosialisas! kepada } \\
\text { KSM baru }\end{array}$ & \multicolumn{2}{|c|}{$\begin{array}{l}\text { SARAN DAN BIAYA PFOYEK } \\
\text { Tempat peiatihan } \\
\text { Pemateri } \\
\text { Konsumsi }\end{array}$} & \\
\hline
\end{tabular}


MATRIKS PERENCANAAN PROYEK 5

NAMA PROYEK : Perbaikan susunan pengurus

JANGKA WAKTU: : 6 bulan

\begin{tabular}{|c|c|c|c|}
\hline $\begin{array}{l}\text { TU JUAN - TU JUAN } \\
\text { DAN KEGIATAN- } \\
\text { KEGIATAN PROYEK: } \\
\text { Meningkatkan kinerja } \\
\text { Pengurus BKM }\end{array}$ & $\begin{array}{l}\text { INDIKATOR-INDIKATOR } \\
\text { OBJEKTIF: } \\
\text { Selur uh pengurus aktif } \\
\text { melaksanakan tugasnya }\end{array}$ & $\begin{array}{l}\text { SUMBER-SUMBER } \\
\text { PEMBUKTIAN: } \\
\text { KetUa BKM }\end{array}$ & $\begin{array}{l}\text { ASUMSI-ASUMSI } \\
\text { PENT ING: }\end{array}$ \\
\hline $\begin{array}{l}\text { SASARAN PROYEK: } \\
\text { Pengurus BKM Berkah } \\
\text { Mul yo }\end{array}$ & $\begin{array}{l}\text { Tercatat sebagai Pengurus } \\
\text { BKM Berkah Mulyo }\end{array}$ & $\begin{array}{l}\text { Susunan Pengurus BKM } \\
\text { Berkah Mulyo }\end{array}$ & \\
\hline $\begin{array}{l}\text { MAKSUD PROYEK: } \\
\text { Merubah susunan } \\
\text { Pengurus BKM Berkah } \\
\text { Mui yo }\end{array}$ & $\begin{array}{l}\text { Pelaksanaan rapat untuk } \\
\text { membentuk pengurus } \\
\text { baru }\end{array}$ & $\begin{array}{l}\text { Daftar hadir rapat dan } \\
\text { noluten kepulusan rapat }\end{array}$ & $\begin{array}{l}\text { Resistensi terhadap } \\
\text { perubahan susunan } \\
\text { pengurus }\end{array}$ \\
\hline $\begin{array}{l}\text { HASIL-HASIL KERJA } \\
\text { PROYEK: } \\
\text { Perubahan susunan } \\
\text { pengurus BKM Berkah } \\
\text { Mulyo dan deskripsi } \\
\text { kerja }\end{array}$ & $\begin{array}{l}\text { Terdapal susunan } \\
\text { pengurus baru }\end{array}$ & $\begin{array}{l}\text { Susunan yang baru } \\
\text { Pengurus BkM Berkah } \\
\text { Mutyo }\end{array}$ & \\
\hline $\begin{array}{l}\text { KEGIATAN-KEGIATAN } \\
\text { PROYEK: } \\
\text { Merubah personalia } \\
\text { Pengurus BKM Berkah } \\
\text { MUlyo dan membuat } \\
\text { deskripsi kerja }\end{array}$ & \multicolumn{2}{|c|}{ SARAN DAN BIAYA PROYEK } & $\begin{array}{l}\text { Kesulitan menentukan } \\
\text { waktu yang tepat }\end{array}$ \\
\hline
\end{tabular}




\section{PENUTUP}

Kesimpulan dari penelitian ini adalah:

1. Permasalahan kekuranglancaran pengembalian bantuan modal kerja bergulir oleh KSM di BKM Berkah Mulyo dipengaruhi oleh faktor situasional, institusional, dan individual. Faktor-faktor terse but tidak berdiri sendiri tetapi mempunyai hubungan saling mempengaruhi. Faktor situasional yang mempengaruhi faktor kondisi perekonomian yang tidak menentu. Faktor institusional yang mempengaruhi adalah KSM, BKM, Fasilitator Kelurahan, dan masyarakat. Faktor individual yang mempengaruhi adalah kondisi anggota KSM.

2. Intervensi yang dapat dilakukan adalah survey di KSM yang mengajukan permohonan bantuan modal kerja. sosialisasi kepada masyarakat, melakukan Pelatihan motivasi dan ketrampilan wirausaha, kewajiban mengikuti pelatihan bagi KSM yang mengajukan permohonan bantuan modal keria, dan perbaikan susunan pengurus.

Menganalisis permasalahan dalam penanggulangan kemiskinan dengan metode ZOPP dalam penelitian ini adalah salah satu upaya kontribusi mengatasi permasalahan sosial dalam perspektif psikologi. Oleh karena itu, saran yang diberikan untuk aplikasi dan penelitian lebih ianjut adalah:

1. Penelitian selanjutnya sebaiknya memperhatikan efektivitas dari intervensi yang diajukan sehingga efektivitas metode ZOPP dapat lebih terukur.

2. Metode ZOPP dapat memberikan banyak kesempatan untuk melakukan pemberdayaan masyarakat ketika dipergunakan untuk menganalisis masalahmasalah sosial tetapi beberapa kelemahan, seperti lemahnya fungsi peran-peran sosial, tingkat representasi dan mental set dari pihak-pihak yang terkait dalam menganalisis, harus lebih diperhat.kan.

3. Salah satu faktor individual yang menjadi permasalahan dałam pengembalian bantuan modal kerja bergulir adalah kondisi anggota KSM. Hal ini perlu diteliti lebih lanjut, misalnya dari variabel locus of control, nilai-nilai yang dominan, adversity quotient, prokastrinasi, dan lain-lain.

\section{DAFTAR PUSTAKA}

. Buku Satu: Pedoman Umum, 1999. Kedaulatan Rakyat. Penanggulangan Kemiskinan. Dillon: Tidak Bisa 'Sambil Lalư'. 19 Juni 2001.

Kedaulatan Rakyat. Tokoh Kita. 28 Juni 2001.

Lembar Pemantauan Petugas Lapangan Keluarga Berencana (PLKB) Kecamatan Wirobrajan, Jogjakarta.

.2001 h ht:

Coleman, J.W., Cressey, D.R., 1987. Social Problems $3^{\text {rd }}$ edition. Harper \& Row Publishers: New York.

Michener, H.A., DeLamater, J.D. 1999. Social Psychology. $4^{\text {th }}$ edition. Harcourt Brace College Publishers: Orlando.

Myers, D.G. 1990. Social Psychology. 6 th edition. McGraw-Hill College: Michigan.

Ramdhani, N. 1996. Pembinaan Jiwa Ke wiraswastaan Pemuda Melalui Kelompok Swadaya Masyarakat. Laporan Penelitian (tidak diterbitkan). Bagian Psikologi Klinis Fakultas Psikologi UGM: Yogyakarta. 
Shaw, M.E., Costanzo, P.R. 1982. Theories of Social Psychology. $2^{\text {nd }}$ edition. McGraw-Hill, Inc: Tokyo.

Stepan, C.W.r. Stepan, W.G. 1985. Two Social Psychologies. An Integrative Approach. The Dorsey: Illinois.
Sucipto, Helly. 1999. Metode Perencanaan Proyek yang Berorientasi pada Tujuan. Buku Panduan Pengayaan Program Profesi Bagian Psikologi Sosial. Program Profesi Bagian Psikologi Sosial Fakultas Psikologi UGM: Yogyakarta.

$+4$ 